\title{
AN EXTRAPOLATION METHODOLOGY FOR POOL FIRE EXTINGUISHMENT BY LOCAL APPLICATION WATER MIST SYSTEMS
}

\author{
Hong-Zeng Yu \\ FM Global Research \\ 1151 Boston-Providence Turnpike \\ Norwood, MA 02062, USA \\ Richard Ferron \\ FM Approvals \\ 743 Reynolds Road \\ West Glocester, RI 02814, USA
}

\author{
Paul H. Dobson \\ FM Global \\ 1151 Boston-Providence Turnpike \\ Norwood, MA 02062, USA \\ Christian Barsamian, Maher Hanna \\ and Victor Gameiro ${ }^{+}$ \\ Securiplex Inc. \\ 549 Meloche Avenue \\ Dorval, Quebec, Canada
}

\begin{abstract}
A series of fire tests was conducted to investigate the requirements for local application water mist systems to provide consistent fire suppression performance for different sizes of open pool fires. These tests were conducted with water mist nozzles arranged above square or rectangular diesel pools. The tests showed that a water mist system gives consistent fire suppression performance for pool fires of different sizes and aspect ratios if the system meets the following requirements: 1) constant nozzle operating conditions; 2) complete pool coverage by water mist sprays, 3) constant inclination angles for individual nozzles, 4) constant ratio of total number of nozzles versus the pool area; 5) constant ratio of overall spray coverage area versus pool area, and 6) constant nozzle elevation in the flaming region above the pool. The tests also showed that fire suppression performance could be improved by lowering the nozzle elevation and increasing the inclination angles of the nozzles along the pool perimeter under the experimental conditions used in this investigation.
\end{abstract}

KEYWORDS: fire suppression, local application water mist systems, pool fires

\section{INTRODUCTION}

The development of water mist fire protection made a strong resurgence after the use of halon was prohibited in the 1987 Montreal Protocol due to halon's destruction of ozone layer. Because of the lack of engineering first principles for the development of water mist systems, extensive full-scale fire testing is required for system development and evaluation, and extrapolation of system applications is generally not permitted by authorities having jurisdiction without further fire testing [1,2]. The requirement of extensive fire testing dramatically increases the development cost of water mist systems.

Investigations on water mist fire protection conducted in the past decade [3-8], mostly experimental, basically re-affirmed the water mist fire suppression mechanisms identified

\footnotetext{
+ Current address: Marioff, Inc., 3600 Commerce Drive, Suite 614, Baltimore, MD 21227, USA.
} 
by Rasbash et al. in the 1950s [9]. The renewed learning process has been benefited little from the relatively much mature, more quantitative sprinkler technology because their dominant fire suppression mechanisms are considerably different. Until very recently, total flooding water mist systems have been the focal point of development. The total flooding systems place more weight on oxygen depletion, oxygen displacement by fire gases and vaporized water, and fire-gas cooling than on direct fuel surface cooling [10], as compared to sprinkler protection. However, fuel surface cooling as well as dilution of fuel vapor appears to be important for local application water mist protection $[9,11,12]$. Although research efforts were devoted to address the different mechanisms of water mist fire suppression as functions of fuel type, overall mist spray characteristics, enclosure geometry and size, ventilation conditions, obstructions, etc [6], the current status of understanding is mainly qualitative. Therefore, full-scale fire testing is still generally required before fully-validated, predictive engineering tools are available. However, it may be possible that the requirement of full-scale fire testing can be reduced somewhat for simple fire scenarios if the fire dynamics is well understood and the extrapolation principles for the water mist systems are established by fire testing.

This paper is to demonstrate that a reduction of fire testing requirement is feasible for pool fires protected by local application water mist systems.

\section{WATER MIST PROTECTION REQUIREMENTS FOR CONSISTENT POOL FIRE SUPPRESSION PERFORMANCE}

For pool fires situated in an open environment, it is believed that dilution of fuel vapor, flame cooling, flame stretching, and cooling of liquid fuel by water mist sprays are the dominant fire suppression mechanisms for a local application water mist system. To maintain constancy of the aforementioned fire suppression mechanisms for different pool sizes, the spatial variations of the following three variables should be reasonably preserved between the water mist nozzles and the pool surface: 1) drop velocity relative to plume velocity, 2) temperature difference between individual drops and fire plume, and 3) drop concentration and size distribution. And the liquid pools should have the following commonalities: 4) similar fuel physiochemical properties, 5) degree of miscibility between fuel and water, 6) fuel temperature, and 7) fuel depth and burning rate.

The first three variables collectively affect the penetration of mist sprays into the fire plume [13], cooling of fire gases [14], and the dilution of fuel vapor by fire products, vaporized water, and entrained air.

The pool surface temperature is influenced by the 4 th to 7 th variables. The 4 th to 6 th variables, together with drop size and velocity, control the extent of drop penetration into the pool surface and pool surface morphology under water sprays [15], and mixing between fuel and water in the pool. The last variable affects the heating of the liquid pool by the pool fire [16].

In the flaming region of the fire plume, the vertical variations of gas temperature and velocity are insensitive to pool size [17], i.e., for a selected fuel, the gas temperature is reasonably constant with the vertical distance above the pool $(\mathrm{Z})$ and the gas velocity is proportional to $Z^{1 / 2}$. Therefore, if water mist nozzles are positioned at an elevation within 
the flaming region of the pool fires, the fire plume characteristics in the region to be encountered by the water mist sprays are expected to be insensitive to pool size.

Based on the above reasoning, a water mist system's fire suppression performance is expected to be insensitive to pool size in a reasonably quiescent environment if the system meets the following specifications to preserve the constancy of the above variables:

1) The characteristics of water mist discharge are unchanged. The characteristics include water discharge rate, gross drop size distribution, drop discharge velocity, spray pattern (solid or hollow; straight or swirl), and spray angle. For dual fluid nozzles, gas (usually air or nitrogen) discharge rate and velocity should also be maintained.

2) The nozzles are in a regular grid pattern and the pool is completely covered by the water mist sprays.

3) The orientations of individual nozzles are constant.

4) The ratio of total number of nozzles in the grid versus the pool area is constant.

5) The ratio of overall spray coverage area versus pool area is constant.

6) The nozzle grid elevation is in the flaming region and constant above the pool.

The above specifications ensure that the overall water mist discharge rate from the system to the pool fire is scaled linearly with the pool area, and the nominal application water mist density on the pool surface is preserved for different pool sizes.

\section{EXPERIMENTAL SETUPS}

A series of fire tests was conducted to verify the hypothesis that a local application water mist system's fire suppression performance is insensitive to pool size if the system meets the above configuration specifications.

\section{Combustible Liquid Pools}

The fuel used in this validation study was diesel, whose temperature ranged from 15 to 25 ${ }^{\circ} \mathrm{C}$ before ignition in this test series.

The fire tests were conducted for five pool sizes with aspect ratios ranging from 1 to 2: 1 x $1 \mathrm{~m}, 2 \times 2 \mathrm{~m}, 2 \times 3 \mathrm{~m}, 2 \times 4 \mathrm{~m}$, and $3 \times 3 \mathrm{~m}$. These pool sizes were obtained by assembling steel pans of three pan units: 1 x $1 \mathrm{~m}, 2 \times 2 \mathrm{~m}$ and $3 \times 3 \mathrm{~m}$. As shown in Figs. 1 and 2 , the $2 \times 3 \mathrm{~m}$ pool was assembled by abutting one $2 \times 2 \mathrm{~m}$ pan and two $1 \times 1 \mathrm{~m}$ pans; the $2 \times 4 \mathrm{~m}$ pool was made of two $2 \times 2 \mathrm{~m}$ pans. Each pan was $10 \mathrm{~cm}$ high. The liquid pool was prepared by first filling the pan with water to a depth of $6 \mathrm{~cm}$ and then adding a layer of $1-\mathrm{cm}$ deep diesel fuel. This resulted in a freeboard of $3 \mathrm{~cm}$.

\section{Water Mist Nozzles}

Two similar Securiplex nozzles were used in the fire tests: Jetmist 10JET90 and Jetmist 12JET90 [18]. These two nozzles are of a dual-fluid type, by which water is atomized 


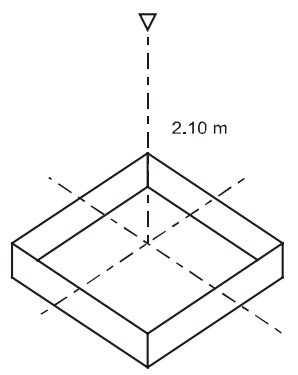

$1 \mathrm{~m} \times 1 \mathrm{~m}$ Pool

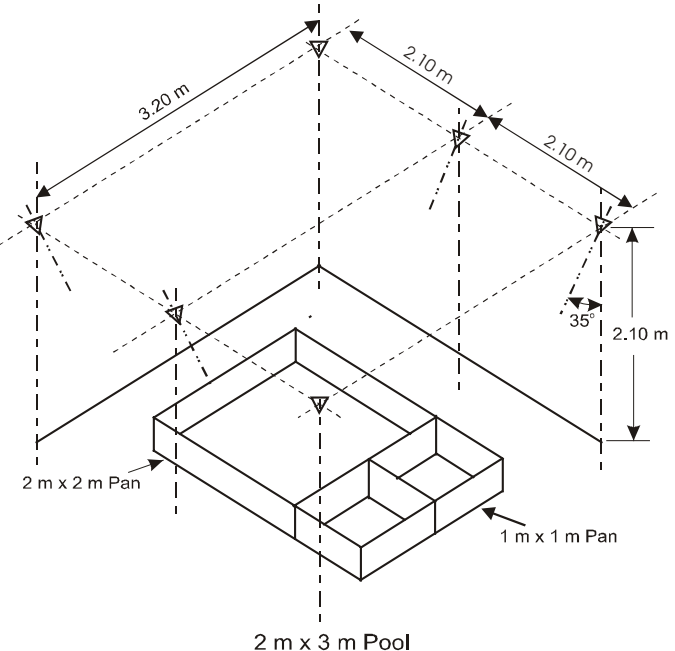

$2 \mathrm{~m} \times 3 \mathrm{~m}$ Pool

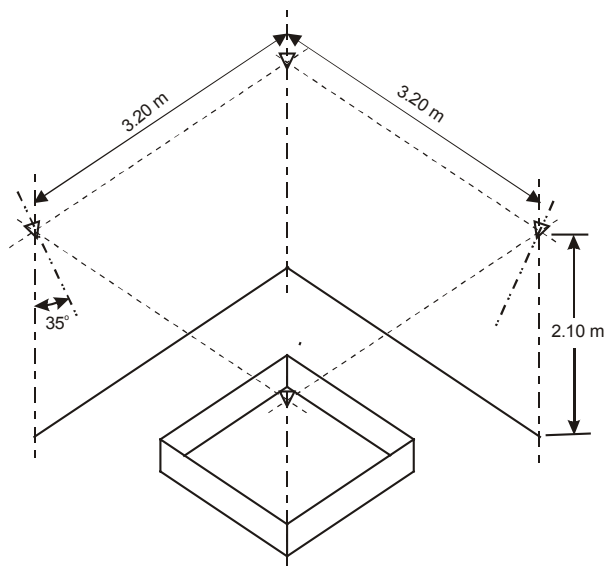

$2 \mathrm{~m} \times 2 \mathrm{~m}$ Pool

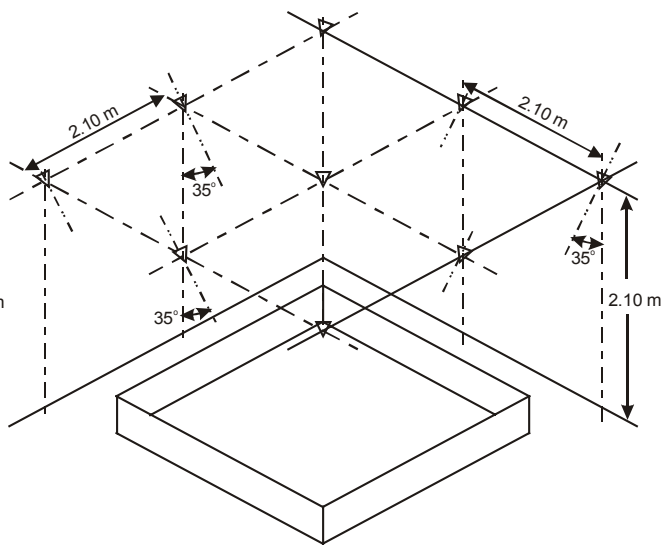

$3 \mathrm{~m} \times 3 \mathrm{~m}$ Pool

Figure. 1 Test setups for water mist nozzles $2.10 \mathrm{~m}$ above the pools. The nozzles along the pool perimeter are inclined $35^{\circ}$ toward the pool center. 

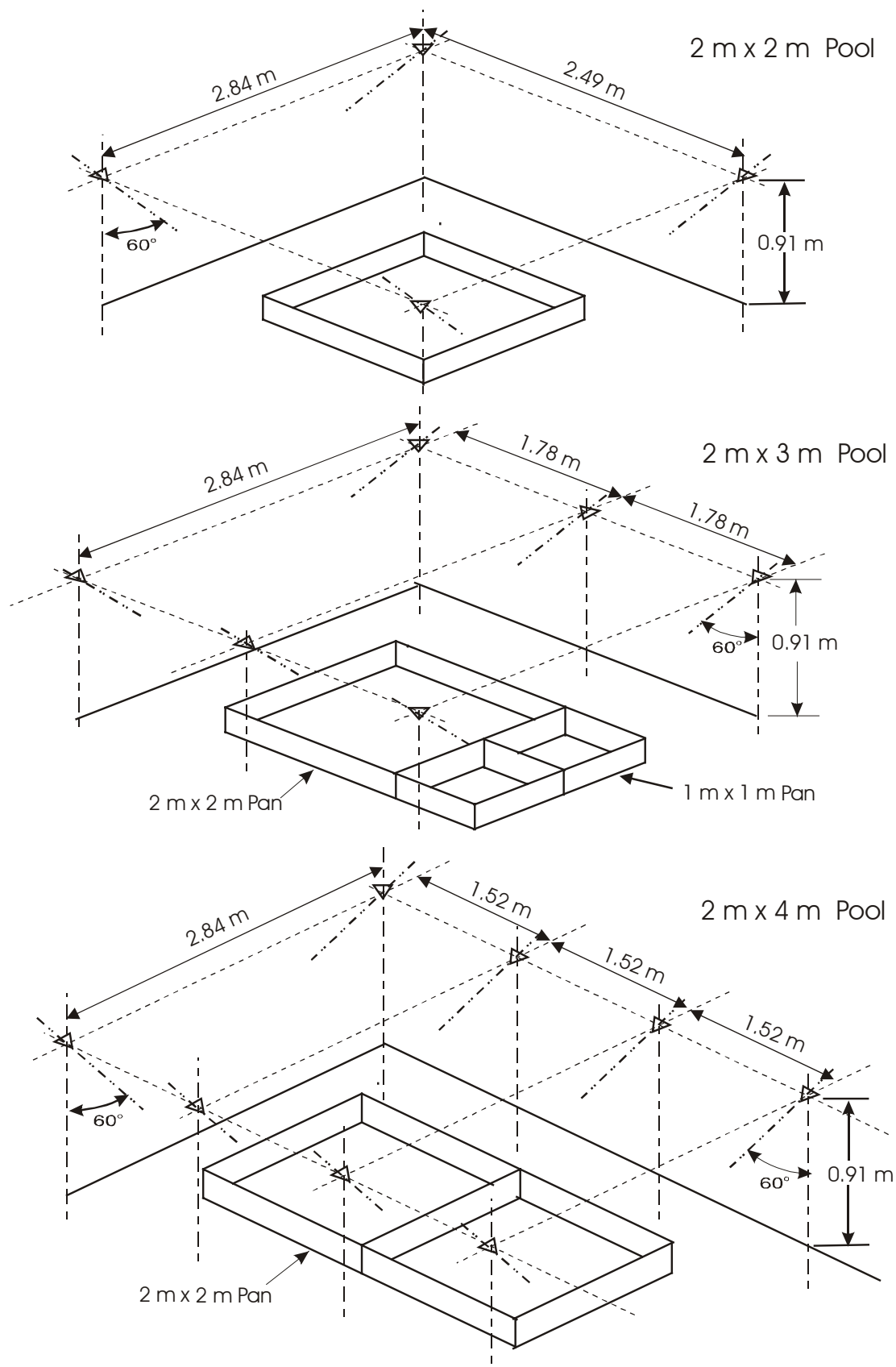

Figure 2 Test setups for water mist nozzles $0.91 \mathrm{~m}$ above the pools. The nozzles are inclined $60^{\circ}$ toward the pool's longitudinal line of symmetry. 


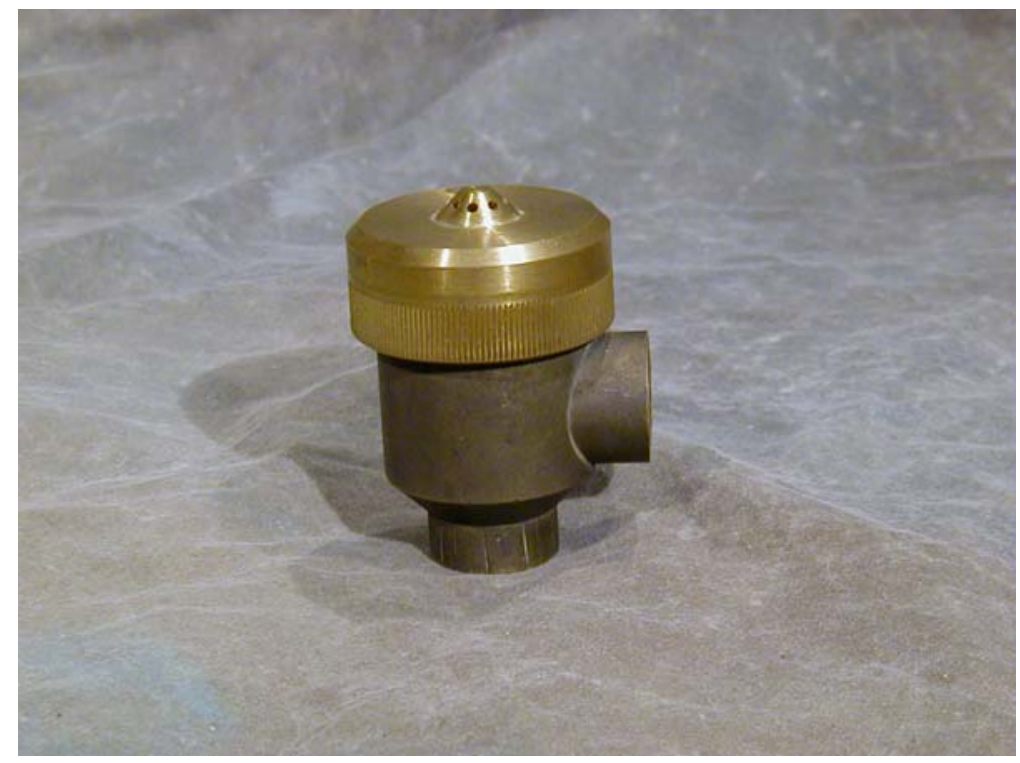

Figure. 3 The nozzle housing for the 10JET90 and 12JET90 nozzles.

by pressurized air. These nozzles have a designated spray angle of 90 degrees. A picture of these nozzles is shown in Fig. 3.

In the tests, the operating pressures for air and water were 6.5 bar and 5.2 bar, respectively. Under these operating pressures, the nominal discharge rates of air (at atmospheric pressure) and water were $453 \mathrm{liters} / \mathrm{min}$ and $8.5 \mathrm{liters} / \mathrm{min}$, respectively, for the Jetmist 10JET90 nozzle, and 496 liters $/ \mathrm{min}$ and 11.5 liters $/ \mathrm{min}$, respectively, for the Jetmist12JET90 nozzle. The above two sets of flow rates were achieved by using different orifice inserts placed inside the same type of nozzle housings. Under these operating conditions, the volumetric median drop diameters at $1 \mathrm{~m}$ from the nozzle ranged from 100 to $150 \mu \mathrm{m}$ within a spray angle of 60 degrees [19]. The water temperatures ranged from 10 to $12{ }^{\circ} \mathrm{C}$ for all the tests conducted in this study.

\section{Nozzle Layouts}

Two sets of fire tests were conducted with nozzles either $0.91 \mathrm{~m}$ or $2.10 \mathrm{~m}$ above the pool surface. The 10JET90 nozzles were used for tests in which the nozzle elevation was 0.91 $\mathrm{m}$ above the pool, while the 12JET90 nozzles were used for tests with nozzles positioned $2.10 \mathrm{~m}$ above the pool.

The 12 JET90 nozzles were used for the following four pool sizes: 1 x $1 \mathrm{~m}, 2 \times 2 \mathrm{~m}, 2 \times 3$ $\mathrm{m}$ and $3 \times 3 \mathrm{~m}$. The nozzle arrangements above these four liquid pools are shown in Fig. 1. As indicated in the figure, one nozzle was used to protect the $1 \times 1-\mathrm{m}$ pool. In order to meet the requirement that the ratio of number of nozzles configured in each system versus the respective pool area is constant, the number of nozzles used for the $2 \mathrm{x}$ $2-\mathrm{m}, 2 \times 3-\mathrm{m}$ and $3 \times 3-\mathrm{m}$ pools was therefore four, six and nine, respectively. Furthermore, to achieve the requirements that the mist spray coverage area is greater than 
the protected pool area and a common water-mist design density is realized on the pool surface, the nozzles were arranged by 1) providing a $0.60-\mathrm{m}$ horizontal offset between the perimeter nozzles and the respective pool edges, and 2) using the following nozzle spacings: $3.20 \times 3.20 \mathrm{~m}$ for the $2 \times 2-\mathrm{m}$ pool, $3.20 \times 2.10 \mathrm{~m}$ for the $2 \times 3-\mathrm{m}$ pool, and $2.10 \times 2.10 \mathrm{~m}$ for the $3 \times 3-\mathrm{m}$ pool. In these configurations, the perimeter nozzles were tilted $35^{\circ}$ from vertical toward the pool center. Table 1 gives the respective spray coverage areas and nominal water mist densities on the plane of pool surface for the above nozzle arrangements.

Table 1

Overall Spray Coverage Areas and Water Mist Densities for Nozzles $2.10 \mathrm{~m}$ above the Pool

\begin{tabular}{|c||c|c|c||}
\hline $\begin{array}{c}\text { Pool Size } \\
(\mathrm{m} \times \mathrm{m})\end{array}$ & $\begin{array}{c}\text { Spray Coverage Area } \\
\left(\mathrm{m}^{2}\right)\end{array}$ & $\begin{array}{c}\text { Ratio of Spray } \\
\text { Coverage Area vs. Pool } \\
\text { Area }\end{array}$ & $\begin{array}{c}\text { Water Mist Density } \\
\left(\text { liters } / \mathrm{m}^{2} / \mathrm{min}\right)\end{array}$ \\
\hline \hline $1 \times 1$ & 1.20 & 1.20 & 9.58 \\
\hline $2 \times 2$ & 4.58 & 1.15 & 10.04 \\
\hline $2 \times 3$ & 6.94 & 1.16 & 9.94 \\
\hline $3 \times 3$ & 10.57 & 1.17 & 9.79 \\
\hline
\end{tabular}

For fire tests conducted with 10JET90 nozzles, the following three pool sizes were used: $2 \times 2 \mathrm{~m}, 2 \times 3 \mathrm{~m}$ and $2 \times 4 \mathrm{~m}$. Since four nozzles were used to protect the $2 \times 2-\mathrm{m}$ pool, the number of nozzles used for the $2 \times 3-\mathrm{m}$ and $2 \times 4-\mathrm{m}$ pools were six and eight, respectively, to maintain a constant ratio of number of nozzles versus pool area. In this set of tests, the nozzles were positioned oppositely in pairs along the two longer sides of the pools. The nozzles were first tilted toward the pool's longitudinal line of symmetry by 60 degrees. The four corner nozzles were then turned azimuthally 45 degrees toward the pool center. The nozzle spacings employed for the above three pool sizes were: $2.84 \mathrm{x}$ $2.49 \mathrm{~m}$ for the $2 \times 2-\mathrm{m}$ pool, $2.84 \times 1.78 \mathrm{~m}$ for the $2 \times 3-\mathrm{m}$ pool, and $2.84 \times 1.52 \mathrm{~m}$ for the $2 \times 4-\mathrm{m}$ pool. Thus, the nozzles were offset from the pools' longer sides by $0.41 \mathrm{~m}$, and by $0.25 \mathrm{~m}$ from the shorter sides of the pools. Table 2 gives the spray coverage areas and nominal water mist densities on the plane of pool surface for the above three nozzle arrangements.

Table 2

$\underline{\text { Overall Spray Coverage Areas and Water Mist Densities for Nozzles } 0.91 \mathrm{~m}}$ above the Pool

\begin{tabular}{|c||c||c|c||}
\hline $\begin{array}{c}\text { Pool Size } \\
(\mathrm{m} \times \mathrm{m})\end{array}$ & $\begin{array}{c}\text { Spray Coverage Area } \\
\left(\mathrm{m}^{2}\right)\end{array}$ & $\begin{array}{c}\text { Ratio of Spray } \\
\text { Coverage Area vs. Pool } \\
\text { Area }\end{array}$ & $\begin{array}{c}\text { Water Mist Density } \\
\left(\text { liters } / \mathrm{m}^{2} / \mathrm{min}\right)\end{array}$ \\
\hline $2 \times 2$ & 4.89 & 1.22 & 6.95 \\
\hline $2 \times 3$ & 7.46 & 1.24 & 6.84 \\
\hline $2 \times 4$ & 9.84 & 1.23 & 6.91 \\
\hline
\end{tabular}




\section{$\underline{\text { Instrumentation }}$}

The following measurements were made in the fire tests: air temperature $1 \mathrm{~m}$ above the test floor, water operating pressure, air operating pressure, total water flow rate to the nozzles, total air flow rate to the nozzles, and the concentrations of $\mathrm{CO}_{2}, \mathrm{CO}$ and $\mathrm{O}_{2}$.

A PC-based data acquisition system was used to collect the data at a rate of one scan per second.

\section{$\underline{\text { Experimental Procedures }}$}

The fire tests were conducted in a $13.7 \times 18.3 \times 11.3 \mathrm{~m}$ high building. The building had two $0.93-\mathrm{m}^{2}$ louver vents near the roof located oppositely on the building's two smaller walls. During the fire tests, a floor-level opening of $3.66 \mathrm{~m}$ wide $\times 1.82 \mathrm{~m}$ high was maintained near a corner on one of the two larger building walls. The smoke exhaust from the building was achieved by natural convection.

The water was pumped with an electric pump and the air was supplied from an air compressor. Before each test, the operating pressures for water and air were adjusted to the designated values by conducting flow calibration. When the designated values were obtained, the supplies of water and air to the nozzles were terminated with respective solenoid shut-off valves.

The individual pans of each pool size were first filled with 6-cm deep water. A 1-cm deep diesel fuel was floated on top of the water. Subsequently, small amount of heptane was spread in the individual pans to enhance the flame spread on the pool surface.

The fuel was ignited with a propane torch. A 30-s pre-burn period was initiated immediately after the flame completely covered the pool surface. The water mist system was manually activated at the end of the pre-burn period.

The water mist discharge was terminated when the fire was completely extinguished. The propane torch was subsequently used to ignite the pool surface to ensure that fire extinguishment was not caused by fuel burnout.

\section{EXPERIMENTAL RESULTS AND DISCUSSIONS}

In this investigation, the fire suppression performance of a water mist system was evaluated based on the time it required to completely extinguish the pool fire.

For all the fire tests conducted in this study, the floor-level air temperature in the building during tests did not exceed $45{ }^{\circ} \mathrm{C}$, and the oxygen concentration was above $20.6 \%$ by volume.

The diesel temperature in the pool was not measured in the tests. Transient heat conduction analysis was performed to estimate the temperature at the bottom of the diesel layer at the end of the pre-burn period. The incident heat fluxes on the pool surface were estimated to range from $66 \mathrm{~kW} / \mathrm{m}^{2}$ for the $1 \times 1-\mathrm{m}$ diesel pool fire to $76 \mathrm{~kW} / \mathrm{m}^{2}$ for the $3 \times 3-\mathrm{m}$ diesel pool fire [20]. Using $76 \mathrm{~kW} / \mathrm{m}^{2}$ and considering the effects of pool surface 
re-radiation and fuel evaporation, the analysis showed that the diesel pool surface reached its boiling point after a fire exposure duration of $9 \mathrm{~s}$. At the end of the 30-s pre-burn period, the diesel temperature at the bottom of the diesel layer was close to the ambient. Therefore, the experimental results obtained in this study were not affected by the characteristics of the substrate (water in this case) beneath the diesel layer.

Figure 4 presents the fire extinguishment times as a function of pool area for the 12JET10 nozzles arranged as shown in Fig. 1. Based on visual observations, the fire extinguishment process was similar for the four diesel pools. The flames along each pan's perimeter tended to persist after the flame in the central area of each pan was extinguished. These persistent flames were later broken down into small flamelets before they were eventually extinguished.

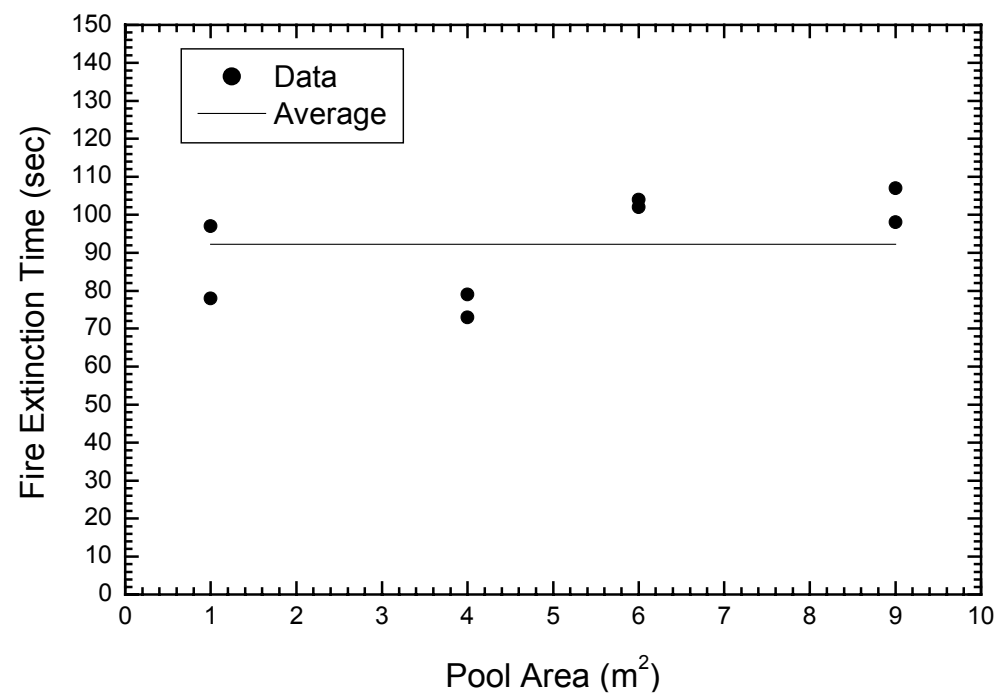

Figure 4. Fire Extinction times versus pool area for mist nozzles $2.10 \mathrm{~m}$ above the pool.

As mentioned previously, it has been recognized that a local application water mist system's ability to extinguish open pool fires depends on how efficiently the system can cool, inert and stretch the flames, while simultaneously cooling the fuel surface and diluting the fuel vapor.

The flames of the four tested pool fires were all taller than the nozzle-grid elevation according to the well-established flame height correlation [21], which was confirmed by visual observation. Since the gas temperature in the flaming region is relatively constant with height, and the gas velocity is only a function of the square root of elevation above the pool surface, it is expected that: 1) the upward plume momentum flux in the flame is mainly a function of elevation, and 2) the water droplets at each elevation between the nozzle grid and the pool surface are subjected to similar convective environment for the four tested pool fires. Furthermore, the fire becomes optically thick when the pool diameter is about $1.5 \mathrm{~m} \mathrm{[22].} \mathrm{As} \mathrm{a} \mathrm{result,} \mathrm{the} \mathrm{water} \mathrm{mist} \mathrm{is} \mathrm{also} \mathrm{subject} \mathrm{to} \mathrm{similar} \mathrm{radiative}$ environment between the nozzle elevation and the pool surface. 
Since the nozzle elevation was maintained constant above the pool and the plume momentum flux is only a function of height above the pool surface, the degree of penetration of the water mist sprays into the fire plume is expected to be independent of pool size if constant rates of air and water mist are discharged at the same respective air and water pressures.

Based on the above discussions, the overall cooling, inerting and stretching of the flames, and pool surface cooling and fuel dilution are expected to be comparable among different pool sizes, which is supported by the relatively constant fire extinguishment times shown in Fig. 4.

Figure 5 shows the times required to extinguish the 2-m wide diesel pool fires as a function of pool area. In this set of tests, the flamelets at the pan corners were noticeably more persistent than those in each pan's central area as compared to the test cases where the nozzles were $2.10 \mathrm{~m}$ above the pool. When the nozzles were lowered to $0.91 \mathrm{~m}$ above the pool, the fire extinction times increased from the $2 \times 2-\mathrm{m}$ pool to the $2 \times 3-\mathrm{m}$ pool, and then decreased toward the $2 \times 4-\mathrm{m}$ pool. In these tests, as shown in Fig. 2, there were 4,12 and 8 corners in the $2 \times 2-\mathrm{m}, 2 \times 3-\mathrm{m}$ and $2 \times 4-\mathrm{m}$ pools, respectively. Therefore, the probability for the presence of corner flamelets was highest for the $2 \times 3-\mathrm{m}$ pool, and lowest for the $2 \times 2-\mathrm{m}$ pool. Even with this corner effect on the fire extinction time, the tested water mist systems with nozzles $0.91 \mathrm{~m}$ above the pool still showed reasonably consistent fire suppression performance for different pool sizes.

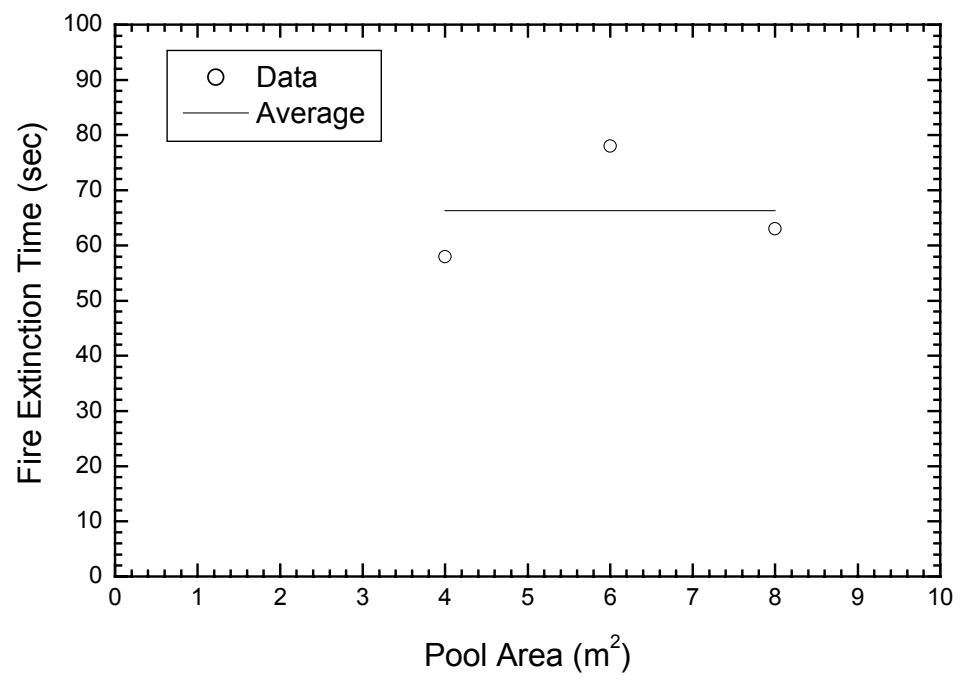

Figure 5 Fire Extinction times versus pool area for mist nozzles $0.91 \mathrm{~m}$ above the pool.

The average of the fire extinction times shown in Fig. 5 is about 66 seconds, which is less than the average of about 92 seconds shown in Fig. 4, although the design mist density corresponding to Fig. 5 is less than that for Fig. 4. It was previously demonstrated that the fire suppression performance could be improved by lowering the nozzle elevation [11]. Based on observation, it is believed that the improved performance was due to 1) greater realized mist density in the vicinity of pool surface to reduce the radiative heat feedback 
to pool surface when the flame in the pool's central area was still present, and 2) stronger mist and air sweeping motion on the pool surface to increase the propensity of blowing flames away from the pool surface. Furthermore, the cooling rate of the pool surface is expected to have been increased due to higher mist density and air velocity. The increase of nozzle inclination angle might have also contributed to improve the pool surface cooling in these tests [23].

\section{CONCLUSIONS}

The requirements for a local application water mist system to provide consistent fire suppression performance for pool fires of different sizes were proposed and validated with fire suppression tests conducted with diesel pool fires. These requirements are: 1) constant characteristics of water mist sprays; 2) complete pool coverage by water mist sprays, 3) constant inclination angles of individual nozzles, 4) constant ratio of total number of nozzles versus pool area; 5) constant ratio of overall spray coverage area versus pool area; 6) constant nozzle elevation in the flaming region above the pool surface.

It is recommended that the above requirements be further validated with other flammable liquids, other types of nozzles, and with pool sizes larger than those used in this investigation.

\section{REFERENCES}

1. Mawhinney, J.R., "The Importance of Fire Testing for the Design of Water Mist Fire Suppression Systems," Fire Protection Engineering 4: 28-36 (1999).

2. Klocke, M., "Water Mist Spray Nozzles - Final Report," CEA-R\&D-Project, CEA GE13 00/08, VdS Schadenverhütung, Köln, Germany, 2000.

3. Finnerty, A.E., McGill, R.L. and Slack, W.A., "Water-Based Halon Replacement Sprays," Report No. ARL-TR-1138, U.S. Army Research Laboratory, Aberdeen Proving Ground, Maryland, 1996.

4. Mawhinney, J.R. and Solomon, R., "Water Mist Fire Suppression Systems," NFPA Fire Protection Handbook (18 $\left.8^{\text {th }} \mathrm{ed}\right)$, Cote A.E. (ed.), National Fire Protection Association, Quincy, Massachusetts, 1997, p. 6/15.

5. Lentati, A.M. and Chelliah, H.K., "Physical, Thermal, and Chemical Effects of Fine Water Droplets in Extinguishing Counterflow Diffusion Flames," Combustion -Proceedings of the $20^{\text {th }}$ International Symposium, The Combustion Institute, Pittsburgh, Pennsylvania, 1998, pp. 2839-2846.

6. Back, G.G., Beyler, C.L., DiNenno, P.J., Hansen, R.L., "Full-Scale Water Mist Design Parameters Testing," Report No. CG-D-03-99, U.S. Coast Guard Research and Development Center, Groton, Connecticut, 1999.

7. Liu, Z. and Kim, A.K., "A Review of Water Mist Fire Suppression Systems," Fire Protection Engineering 10, 3: 32-50 (2000).

8. Mesli, B., Quilgars, A., Chauveau, C. and Gökalp, I., "Extinction Limits of Opposed Jet Turbulent Premixed Methane Air Flames with Water Mist," Fire Safety Science -- Proceedings of the $6^{\text {th }}$ International Symposium, International Association for Fire Safety Science, Bethesda, Maryland, 2000, pp. 445-456. 
9. Rasbash, D.J., Rogowski, Z.W. and Stark, G.W.V., "Mechanisms of Extinction of Liquid Fires with Water Sprays," Combustion and Flame 4: 229-234 (1960).

10. Bill, R.G. Jr and Ural, E.A., "Water Mist Protection of Combustion Turbine Enclosures," Fire Safety Science -- Proceedings of the $6^{\text {th }}$ International Symposium, International Association for Fire Safety Science, Bethesda, Maryland, 2000, pp. 457-468.

11. Kokkala, M., "Fixed water sprays against open liquid pool fire," Fire SuppressionResearch -- Proceedings of the $1^{\text {st }}$ International Conference, Stockholm, May 5-8, 1992, pp. 129-158,.

12. Kim, M.B., Jang, Y.J. and Kim, J.K., "Burning Rate of a Pool Fire with Downwarddirected Sprays," Fire Safety Journal 27: 37-48 (1996).

13. Nam, S., "Numerical Simulation of the Penetration Capability of Sprinkler Sprays," Fire Safety Journal 32: 307-329 (1999).

14. Yu, H-Z, Kung, H-C and Han, Z, "Spray Cooling in Room Fires," Combustion, Proceedings of the $21^{\text {st }}$ International Symposium, The Combustion Institute, Pittsburgh, Pennsylvania, 1988, pp. 129-136.

15. Rein, M., "The Transitional Regime between Coalescing and Splashing Drops," J. Fluid Mechanics 306: 145-165 (1996).

16. Modak, A.T., "Ignitability of High-Fire-Point Liquid Spills," NP-1731, Research Project 1165-1, Electric Power Research Institute, Palo Alto, California, 1981.

17. McCaffrey, B., "Purely Buoyant Diffusion Flames: Some Experimental Results," NBSIR 79-1910, National Bureau of Standards, Department of Commerce, 1979.

18. Design and Application Manual: Fire Extinguishment Systems for Local Application Systems, Fire-Scope 2000, Document No. E0-15980-00, Securiplex Inc., Quebec, Canada, 2001.

19. Mawhinney, R.R., "Measurements of Drop Size Distributions of Securiplex $90^{\circ}$ Jetmist Air Atomizing Nozzle," Report No. A-4203.2, National Research Council, Canada, 1994.

20. Drysdale, D., An Introduction to Fire Dynamics, John Wiley and Sons, 1985.

21. Heskestad, G., "Luminous Heights of Turbulent Diffusion Flames," Fire Safety Journal 5: 103-108 (1983).

22. Mudan, K.S. and Croce, P.A., "Fire Hazard Calculations for Large Open Hydrocarbon Fires," The SFPE Handbook of Fire Protection Engineering( $2^{\text {nd }}$ ed) DiNenno P.J. (ed.), National Fire Protection Association, Quincy, Massachusetts, 1995, p. 3/11.

23. Stevens, J. and Webb B.W., "The Effect of Inclination on Local Heat Transfer under an Axisymmetric, Free Liquid Jet," Int. J. Heat Mass Transfer 34, 4/5: 1227-1236 (1991). 